Xu Ning, Yun-Lian Shi, Xu-Gen Shi, Wen-Li Yang* and Da-Yong Peng*

\title{
Crystal structure of $\boldsymbol{N}$-(methyl(oxo)(1-(6- (trifluoromethyl)pyridin-3-yl)ethyl)- $\lambda^{6}$ - sulfanylidene)cyanamide, $\mathrm{C}_{10} \mathrm{H}_{10} \mathrm{~F}_{3} \mathrm{~N}_{3} \mathrm{OS}$
}

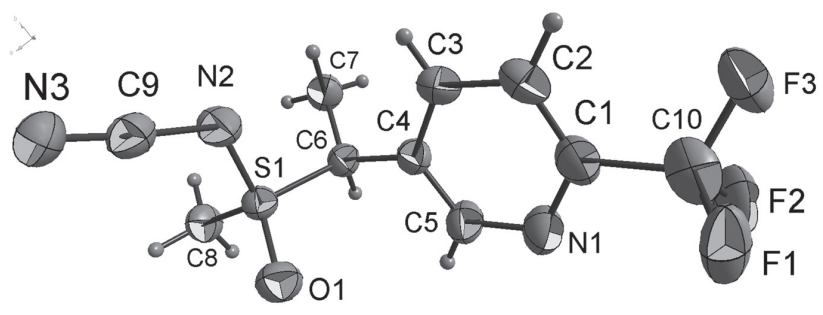

https://doi.org/10.1515/ncrs-2020-0059

Received January 30, 2020; accepted February 27, 2020; available online March 18, 2020

\section{Abstract}

[ $\mathrm{C}_{10} \mathrm{H}_{10} \mathrm{~F}_{3} \mathrm{~N}_{3} \mathrm{OS}$ ], monoclinic, $P 2_{1} / c$ (no. 14), $a=18.555(10) \AA$, $b=6.785(4) \AA, c=10.139(5) \AA, \beta=105.86^{\circ}, V=1227.9(11) \AA^{3}$, $Z=4, R_{\mathrm{gt}}(F)=0.0571, w R_{\mathrm{ref}}\left(F^{2}\right)=0.1785, T=296(2) \mathrm{K}$.

\section{CCDC no.: 1986677}

The molecular structure is shown in the figure. Table 1 contains crystallographic data and Table 2 contains the list of the atoms including atomic coordinates and displacement parameters.

\section{Source of material}

The synthesis process of the title compound was carried out using (Z)- $N$-(methyl(1-(6-(trifluoromethyl)pyridin-3-yl) ethyl)- $\lambda^{4}$-sulfanylidene)cyanamide for start material, using an oxidation reaction [3-6]. A solution of (Z)- $\mathrm{N}$-(methyl (1-(6-(trifluoromethyl)pyridin-3-yl)ethyl)-sulfanylidene) cyanamide $(5.75 \mathrm{~g}, 22 \mathrm{mmol})$ in acetonitrile $(50 \mathrm{~mL})$ was cooled in an ice bath at $5^{\circ} \mathrm{C}$. To the well stirred solution

*Corresponding authors: Wen-Li Yang, College of Water Conservancy and Ecological Engineering, Nanchang Institute of Technology, Nanchang 330000, P.R. China, e-mail: szyangwl@163.com; and Da-Yong Peng, College of Sciences, Jiangxi Agricultural University, Nanchang 330045, P.R. China, e-mail: dayongpeng@163.com. https://orcid.org/00000003-2527-8714

Xu Ning: College of Land Resource and Environment, Jiangxi Agricultural University, Nanchang 330045, P.R. China Yun-Lian Shi and Xu-Gen Shi: College of Agronomy, Jiangxi Agricultural University, Nanchang 330045, P.R. China
Table 1: Data collection and handling.

\begin{tabular}{ll}
\hline Crystal: & Colourless block \\
Size: & $0.17 \times 0.15 \times 0.13 \mathrm{~mm}$ \\
Wavelength: & Mo $K \alpha$ radiation $(0.71073 \AA)$ \\
$\mu:$ & $0.29 \mathrm{~mm}^{-1}$ \\
Diffractometer, scan mode: & Bruker APEX-II, $\varphi$ and $\omega$ \\
$\theta_{\text {max }}$, completeness: & $25.5^{\circ},>99 \%$ \\
$N(h k l)_{\text {measured }}, N(h k l)_{\text {unique }}, R_{\text {int }}:$ & $8810,2281,0.031$ \\
Criterion for $I_{\text {obs }}, N\left(h k l_{\mathrm{gt}}:\right.$ & $I_{\text {obs }}>2 \sigma\left(I_{\text {obs }}\right), 1978$ \\
$N(\text { param })_{\text {refined }}:$ & 165 \\
Programs: & Bruker [1], SHELX [2] \\
\hline
\end{tabular}

Table 2: Fractional atomic coordinates and isotropic or equivalent isotropic displacement parameters $\left(\AA^{2}\right)$.

\begin{tabular}{lrrrr}
\hline Atom & $\boldsymbol{x}$ & $\boldsymbol{y}$ & $\boldsymbol{z}$ & \multicolumn{1}{c}{$\boldsymbol{U}_{\text {iso }}{ }^{*} \boldsymbol{U}_{\text {eq }}$} \\
\hline C1 & $0.36996(17)$ & $1.0306(5)$ & $1.0228(3)$ & $0.0536(8)$ \\
C2 & $0.37549(19)$ & $0.8294(5)$ & $1.0327(4)$ & $0.0626(9)$ \\
H2 & 0.4160 & 0.7705 & 1.0952 & $0.075^{*}$ \\
C3 & $0.32012(18)$ & $0.7159(5)$ & $0.9486(4)$ & $0.0556(8)$ \\
H3 & 0.3225 & 0.5791 & 0.9532 & $0.067^{*}$ \\
C4 & $0.26132(16)$ & $0.8091(4)$ & $0.8577(3)$ & $0.0420(7)$ \\
C5 & $0.26111(18)$ & $1.0135(5)$ & $0.8571(3)$ & $0.0547(8)$ \\
H5 & 0.2212 & 1.0768 & 0.7961 & $0.066^{*}$ \\
C6 & $0.19847(16)$ & $0.7000(4)$ & $0.7587(3)$ & $0.0410(6)$ \\
H6 & 0.1792 & 0.7873 & 0.6800 & $0.049^{*}$ \\
C7 & $0.22099(19)$ & $0.5094(5)$ & $0.7032(4)$ & $0.0531(8)$ \\
H7A & 0.2569 & 0.5368 & 0.6531 & $0.080^{*}$ \\
H7B & 0.1775 & 0.4485 & 0.6433 & $0.080^{*}$ \\
H7C & 0.2428 & 0.4220 & 0.7779 & $0.080^{*}$ \\
C8 & $0.4264(2)$ & $1.1649(7)$ & $1.1121(5)$ & $0.0740(11)$ \\
C9 & $0.10955(16)$ & $0.4215(4)$ & $1.0105(3)$ & $0.0443(7)$ \\
C10 & $0.04478(17)$ & $0.6009(5)$ & $0.7066(3)$ & $0.0500(7)$ \\
H10A & 0.0023 & 0.5885 & 0.7427 & $0.075^{*}$ \\
H10B & 0.0537 & 0.4775 & 0.6675 & $0.075^{*}$ \\
H10C & 0.0351 & 0.7011 & 0.6372 & $0.075^{*}$ \\
N1 & $0.31390(16)$ & $1.1252(4)$ & $0.9374(3)$ & $0.0572(7)$ \\
N2 & $0.15227(15)$ & $0.4864(4)$ & $0.9348(3)$ & $0.0554(7)$ \\
N3 & $0.07752(19)$ & $0.3587(5)$ & $1.0833(3)$ & $0.0650(8)$ \\
O1 & $0.10801(12)$ & $0.8458(3)$ & $0.9005(2)$ & $0.0521(6)$ \\
S1 & $0.12346(4)$ & $0.66558(10)$ & $0.83841(7)$ & $0.0377(3)$ \\
F1 & $0.4836(2)$ & $1.0772(6)$ & $1.1837(6)$ & $0.202(3)$ \\
F2 & $0.4536(2)$ & $1.2948(6)$ & $1.0421(4)$ & $0.1454(15)$ \\
F3 & $0.3980(2)$ & $1.2778(8)$ & $1.1862(5)$ & $0.167(2)$ \\
\hline & & & &
\end{tabular}

This work is licensed under the Creative Commons Attribution 4.0 Public 
was added ( $8.0 \mathrm{~g}, 22 \mathrm{mmol})$ of a $40 \%$ aqueous solution of $\mathrm{NaMnO}_{4}$ over $0.5 \mathrm{~h}$. During the addition the reaction temperature increased to about $20^{\circ} \mathrm{C}$. The resulting brown reaction slurry was allowed to stir for about $0.5 \mathrm{~h}$ and then cooled to about $5{ }^{\circ} \mathrm{C}$. A $30 \%$ aqueous solution of sodium metabisulfite (29.8 g, $47 \mathrm{mmol}$ ) was added to the vigorously stired reaction mixture in one portion. The temperature increased by 15 to $20{ }^{\circ} \mathrm{C}$ during the course of the addition, and then the reaction mixture slurry thickened. Additional acetonitrile $(15 \mathrm{~mL})$ and water $(15 \mathrm{~mL})$ were added to facilitate mixing. The collected grey solids were rinsed with acetonitrile $(15 \mathrm{~mL})$. The combined filtrate and wash was transferred to a separatory funnel. The lower aqueous phase was removed. The organic phase was concentrated in vacuo; the residue was purified by column chromatography (ethyl acetate/hexane $=1 / 1$ ) to give the title compound $(5.2 \mathrm{~g})$, Yield $83.38 \%$. The product was recrystallized from isopropyl alcohol. m.p. $139^{\circ} \mathrm{C}-141{ }^{\circ} \mathrm{C}$. Elemental Anal. Calcd. (\%) for $\mathrm{C}_{10} \mathrm{H}_{10} \mathrm{~F}_{3} \mathrm{~N}_{3} \mathrm{OS}$ : C, 43.32; H, 3.64; N, 15.16; Found(\%): C, 41.96; H, 3.87; N, 14.68 .

\section{Experimental details}

All $\mathrm{H}$ atoms were included in calculated positions and refined as riding atoms, with $\mathrm{C}-\mathrm{H}=0.93 \AA$ with $U_{\text {iso }}(\mathrm{H})=1.5 U_{\text {eq }}(\mathrm{C})$ for methyl $\mathrm{H}$ atoms and $1.2 U_{\text {eq }}(\mathrm{C})$ for all other $\mathrm{H}$ atoms.

\section{Comment}

Sulfoxaflor a new insecticide from Dow Agrosciences was sold for the first time in 2012, and the first product from this new class (the sulfoximines) of insect control agents, exhibits broad-spectrum efficacy against many sap-feeding insect pests, including aphids, white flies, hoppers, and lygus, with levels of activity that are comparable to those of other classes of insecticides [7-10]. Herein we report the crystal structure of Sulfoxaflor. The crystal structure may lead to a better understanding of mechanisms, which makes this kind of compound better understood and paves the way for the development of more novel sulfoximine compounds.

In the molecule of the title compound, bond lengths and angles are very similar to those given in the literature [11-13]. The molecular conformation is characterized by the C5-C4-C6-C7, C5-C4-C6-S1, C4-C6-S1-C8, and C4C6-S1-N2 torsion angles of $-144.8^{\circ}, 88.2^{\circ},-164.6^{\circ}$, and $79.5^{\circ}$, respectively.

Acknowledgements: X-ray data were collected at Instrumental Analysis Center Nanchang Hangkong University, Nanchang, 330063, People's Republic of China. This research has been supported by The "13th Five-Year" National Key Research Program of China (2017YFD0301604), the National
Natural Science Foundation of China (21562022), Science \& Technology Transformation Program for Universities in Jiangxi Province (KJLD14095), The Natural Science Foundation of Jiangxi Province (Grant No. 20181BAB203015).

\section{References}

1. Bruker. APEX2, SAINT and SADABS. Bruker AXS Inc., Madison, WI, USA (2009).

2. Sheldrick, G. M.: A short history of SHELX. Acta Crystallogr. A64 (2008) 112-122.

3. Arndt, K. E.; Bland, D. C.; Podhorez, D. E.; Mcconnell, J. R.: Process for the oxidation of certain substituted sulfilimines to insecticidal sulfoximines. US: W02008097235, 2008-08-14.

4. Podhorez Jr, D. E.; R. R.; Mcconnell, J. R.: Process for the preparation of certain substituted sulfilimines. US: US2008207910, 2008-08-28

5. Liu, A.; Zhou, Q.; Shen, Q.; Du, C.: Study of synthetic process of novel pesticides sulfoxaflor. Chin. J. Organo-Fluorine Industry. 3 (2012) 5-7.

6. Wu, E.; Yu, H.; Song, Y.; Liang, B.; Wang, J.; Li, B.: Synthesis and insecticidal activity of sulfoxaflor. Chin. J. Agrochemicals 50 (2011) 23-25.

7. Zhu, Y.; Loso, M. R.; Watson, G. B.; Sparks, T. C.; Thomas, J. D.: Discovery and characterization of sulfoxaflor, a novel insecticide targeting sap-feeding pests. J. Agric. Food. Chem. 59 (2010) 2950-2957.

8. Jonathan, M. B.; Clifford, B. G.; Jim, X. H.; Michael, R. L.; Genta, N.; Steven, P. N.; Richard, B. R.; Thomas, C. S.; James, T.; Gerald, B. W.; Zhu, Y.: Biological characterization of sulfoxaflor, a novel insecticide. Pest Manag. Sci. 67 (2011) 328-334.

9. Arndt, K. E.; Bland, D. C.; Irvine, N. M.; Powers, S. L.; Martin, T. P.; Mcconnell, J. R.: Development of a scalable process for the crop protection agent isoclast. Org. Process Res. Dev. 19 (2015) 454-462.

10. Cutler, P.; Slater, R.; Edmunds, A. J.; Maienfisch, P.; Hall, R. G.; Earley, F. G.: Investigating the mode of action of sulfoxaflor: $a$ fourth generation neonicotinoid. Pest Manag. Sci. 69 (2013) 607-619.

11. Brown, T. J.; Chapman, R. F.; Cook, D. C.; Hart, T. W.; McLay, I. M.; Jordan, R.; Mason, J. S.; Palfreyman, M. N.; Walsh, R. J. A.; Withnall, M. T.; Aloup, J. C.; Cavero, I.; Farge, D.; James, C.; Mondot, S.: Synthesis and biological activity of trans $-( \pm)-N$ methyl-2-(3-pyridyl)-2-tetrahydrothiopyrancarbothioamide 1-oxide (RP 49356) and analogues: a new class of potassium channel opener. J. Med. Chem. 35 (1992) 3613-3624.

12. Mao, W. T.; Zong, G. N.; Fan, Z. J.; Li, F. Y.; Song, H. B.; Li, J. J.; Tatiana, K. A.; Inna, K.; Ksenia, L.; Yury, M. Y.; Nataliya, B. P.: Synthesis, crystal structure and biological activity of $\mathrm{N}$-cyanosulfoximine derivative containing 1,2,3-thiadiazole. Chin. J. Struct. Chem. 34 (2015) 1428-1433.

13. Eccles, K. S.; Stokes, S. P.; Daly, C. A.; Barry, N. M.; McSweeney, S. P.; O’Neill, D. J.; Kelly, D. M.; Jennings, W. B.; Dhubhghaill, O. M. N.; Moynihan, H. A.; Maguire, A. R.; Lawrence, S. E.: Evaluation of the Bruker SMART X2S: crystallography for the nonspecialist? J. Appl. Crystallogr. 44 (2011) 213-215. 